\title{
DIVERSIDADE RELIGIOSA NA PERIFERIA: COMUNIDADE, PODER E RELIGIÃO EM CIDADES BRASILEIRAS ${ }^{1}$
}

\author{
Francisco Pereira Neto ${ }^{2}$
}

Resumo: Este texto trata de uma reflexão sobre dois momentos de uma pesquisa etnográfica que aborda a religiosidade popular e sua presença na constituição de espaços societários nas periferias das cidades de Porto Alegre e de Juiz de Fora, no Brasil. Como perspectiva, essa pesquisa procurou tratar o tema da religião de uma forma transversal, pois retira a exclusividade dos elementos doutrinários e/ou organizacionais internos às religiōes na conformação do objeto de pesquisa. Num primeiro momento o estudo procurou abordar o fenômeno religioso, enfatizando sua presença numa rede de relações que se justificava pela adesão de agentes e de agências a práticas de cuidado social. Nesse caso a rede é definida pelo percurso da etnografia e estão ressaltadas as dimensões religiosas e políticas da realidade estudada. Num segundo momento, e como decorrência do primeiro estudo, a dimensão territorial fica mais explícita e a presença da "organização religiosa" toma o primeiro plano da observação etnográfica. O que se pretende nesta reflexão é apresentar formas distintas de definir o religioso como objeto de estudo, demonstrando que o fenômeno pode apresentar dimensões diferentes e igualmente importantes, dependendo de sua articulação nas situações que compõem a vida social das cidades.

Palavras-chave: Religiosidade popular; Etnografia; Cidade.

Abstract: This text is about a reflexion on two moments of an ethnographic research that deals with popular religiosity and its presence in the constitution of societal spaces in the outskirts of the cities of Porto Alegre and Juiz de Fora, in Brazil. As for the perspective, this work sought to address the subject of religion in a transversal way, not considering the exclusivity of doctrinal and/or organizational

1 Este texto foi produzido para minha participação no Ciclo de Debates: Relatos de Pesquisa, promovido pelo Núcleo de Antropologia e Cidadania (NACi/UFRGS).

2 Professor do Departamento de Antropologia e do Programa de Pós-Graduação em Antropologia da Universidade Federal de Pelotas. E-mail: francisco.fpneto@gmail.com

Debates do NER, Porto Alegre, ANo I4, N. 24, P. I95-22I, JUl./DeZ. 2013 
elements intrinsic to religions in the conformation of the study object. Firstly, the study addressed the religious phenomenon emphasizing its presence in a network of relations which justified itself by the accession of agents and agencies from social care practices. In this case, the network is defined by the ethnographic course, pointing out religious and political dimensions of the studied reality. Secondly, and as a result of the previous study, the territorial dimension is more explicit and the presence of "religious organization" takes the forefront of the ethnographic observation. What is intended in this reflexion is to present distinct ways of defining the religious as the object of study, showing that the phenomenon may display different but equally important dimensions, depending on its articulation in situations which are part of the cities' social life.

Keywords: Popular religiosity; Ethnography; City.

\section{O PROBLEMA DE PESQUISA}

Em 1997, os estudos sobre religião nas áreas da antropologia e da sociologia brasileira se dividiam em duas abordagens importantes. Uma procurava descrever a especificidade da formação religiosa brasileira, destacando nossa "sociogênese" - nas palavras de Sanchis (1997) - através das relações entre as tradiçõos religiosas de "povos desenraizados" que se estabeleceram no Brasil no período colonial. Aqui basicamente as relações entre tradições europeia, africana e nativa conformariam o cenário religioso brasileiro, estendendo suas influências para o processo de construção da nação brasileira e para as relaçôes de poder próprias a esse processo.

Essa discussão tem uma longa tradição no Brasil e remonta aos debates sobre a civilização brasileira levados adiante por Nina Rodrigues, Euclides da Cunha e pelas formulaçôes de Gilberto Freyre sobre a cultura brasileira, além dos estudos de Roger Bastide sobre as religiōes de tradição africana no Brasil. Aqui o tema da religião passava claramente por uma discussão sobre a formação da nação brasileira e a modernidade ou a falta de modernidade que ela propunha. Enquanto Nina Rodrigues e Euclides da Cunha defendiam uma perspectiva claramente evolucionista, procurando ressaltar elementos culturais, raciais e da religiosidade brasileira que estariam "atra-

Debates do NER, Porto Alegre, ANo I4, N. 24, P. I95-22I, JUl./DEZ. 2013 
sando" nossa evolução como sociedade e como povo civilizado, autores como Gilberto Freyre e Roger Bastide procuravam tornar mais complexo o quadro de constituição da sociedade brasileira, especialmente através de suas relações no espaço da cultura e da religiosidade. Para os primeiros, a modernidade era um fato dado, com seus princípios de desenvolvimento colocados, bastando saber como uma nação e seu povo poderiam trilhar esse caminho de uma forma mais eficiente. Para Freyre, e também para Bastide, a modernidade era um tema a ser discutido, sem que estivessem claras as influências que seus elementos teriam na configuração da sociedade brasileira. Ao enfatizar as particularidades do processo de constituição da sociedade brasileira em seus elementos culturais e religiosos, estes autores abrem espaço para problematizar a modernidade no Brasil, seja positivando seus elementos culturais como expressão da criatividade local ou mesmo ressaltando os elementos de resistência da religiosidade africana à imposição da racionalidade moderna no país.

Em 1997, esses problemas levantados por Freyre e Bastide eram atualizados pelo debate sobre sincretismo religioso e globalização, especialmente através das formulações de autores como Pierre Sanchis, José Jorge de Carvalho e Rita Segato sobre o tema. Fundamentalmente, estes autores dão ênfase na dimensão simbólica e nas relações de poder desse processo de formação da cultura e da religiosidade brasileira, afastando a discussão dos essencialismos culturais e raciais, mas mantendo a abordagem através dos elementos criativos próprios a experiência cultural e religiosa surgidos nesse processo. Ou seja, a modernidade não é algo dado, mas uma questão a ser discutida no âmbito da realidade brasileira.

A outra abordagem procurava enfatizar o fenômeno religioso no Brasil como um epifenômeno do processo de modernização na sociedade brasileira. Menos interessada em destacar a especificidade dos elementos constitutivos de uma cultura ou de uma religiosidade brasileira, esses estudos procuravam mostrar como os fenômenos religiosos no Brasil expressavam o desenvolvimento do sistema de valores que levaria o Brasil à condição de uma sociedade moderna; ou seja, ao estabelecimento do individualismo e da democracia modernos no país. Nessa abordagem, sobressaía a referência

Debates do NER, Porto Alegre, ANo I4, N. 24, P. I95-22I, JUl./DeZ. 2013 
às teorias weberianas sobre modernidade e tinham como defensores a escola paulista e "uspiana" de sociologia da religião, representada por autores como Flávio Pierucci (1997; 1998) e Reginaldo Prandi (1992), esses, por sua vez, devedores da sociologia da religião inaugurada por Procópio Camargo nos anos 50 e 60. Camargo, de forma criativa, muda o enfoque dos estudos da religião, centrados no problema da formação da nação, e coloca o foco na religião como algo próprio ao processo de urbanização da sociedade brasileira - quando desenvolve a ideia do continuum mediúnico. Com esse movimento teórico, a especificidade das tradiçōes religiosas brasileiras fica sendo vista como expressão do pluralismo religioso brasileiro e do processo de secularização a que a sociedade brasileira estava submetida, assim como todo o ocidente. Esse tipo de abordagem define a filiação weberiana, pois concebe a modernidade como algo próprio ao processo de evolução da religião na sociedade ocidental - e não a representação da lógica contrária; mas, por outro lado, não enfatiza suficientemente o fato de que a análise weberiana é circunscrita historicamente para o caso europeu. O problema de tal procedimento é a generalização indiscriminada dos preceitos da modernidade europeia para a definição de realidades muito distintas. $\mathrm{O}$ que deveria ser um modelo teórico, operado através da metodologia do tipo ideal, é tomado como descrição objetiva da realidade.

Por outro lado, a perspectiva modernizante coloca a cultura e a religião como temas importantes para pensar as transformações da sociedade contemporânea e suas lógicas de produção de sentido. Relacionar religiosidade popular com urbanização ou diversidade religiosa com secularização implica dizer que os problemas colocados pela religião estão no centro da produção de uma "consciência contemporânea", mesmo que, em alguns casos, essa "consciência" esteja inexoravelmente vinculada ao processo de "desencantamento do mundo". O avanço surge do fato do tema da cultura e da religião não ficarem circunscritos à condição de resistência a uma lógica dominante ou à expressão de uma especificidade autóctone, sem muita relação com as transformações nas outras sociedades no nível global.

É possível perceber que essas abordagens, sob diferentes pontos de vista, colocam em foco nos estudos sobre religião o problema da relação entre o

Debates do NER, Porto Alegre, ANo I4, N. 24, P. I95-22I, JUl./DEZ. 2013 
particular e o universal para o entendimento das realidades societárias. A religiosidade brasileira representaria uma particularidade criativa na sociedade brasileira e uma modernidade que precisava ser vista na sua singularidade? O pensamento mágico presente em algumas de suas expressóes representaria a força de espaços sociais e culturais pouco influenciados pelos valores da secularização e de seu mundo desencantado? Ou, por outro lado, o que se observaria no Brasil é mais uma variação do processo de pluralismo religioso e, em consequência, do avanço de valores seculares e democráticos modernos estabelecidos pelo modelo weberiano de constituição da modernidade?

Na verdade, em 1997, esses modelos interpretativos e analíticos estavam sendo pressionados pelas questôes empíricas e teóricas colocadas pela intensificação dos efeitos do processo de globalização no mundo. As questões sobre a relação entre global e local trazem complexidade às definiçôes sobre a relação entre o particular e o universal na conformação das sociedades contemporâneas. Nem um particularismo monolítico, descrevendo sociedades nacionais como realidades autocontidas, em busca de um "caráter" nacional; nem um universalismo determinista, descrevendo uma realidade substantiva representada pela racionalidade própria a uma sociedade secular, individualista e democrática.

Do meu ponto de vista, fica insinuado que para entender o processo de intensificação de conexões entre as regiōes do mundo seria pertinente entender o fluxo dessas influências nas sociedades locais. Para tanto, é fundamental repensar a concepção do universal como algo que submete ou sintetiza o que é particular. A ênfase deve estar na inter-relação entre o global e o local e na capacidade desse processo de demonstrar a influência mútua de seus elementos na constituição da realidade social. A ênfase na globalização vista como "perspectiva" (Velho, 1997) oferece a possibilidade de rever os elementos epistemológicos nos estudos dos fenômenos sociais, permitindo uma base maior de comparação entre realidades sociais em conexão e, especialmente, que a comparação privilegie o "intermédio", a relação, a interrelação, o fluxo e as fronteiras dos fenômenos sociais estudados, evitando que as sociedades descrevam paisagens estáticas. Aqui, procuro chamar a atenção

Debates do NER, Porto Alegre, ANo I4, N. 24, P. I95-22I, JUl./DEZ. 2013 
para a possibilidade que essa perspectiva oferece de se evitar conceber cultura ou identidade como realidades substantivas (Marcus, 1991).

Diante dessas questóes é que me senti instado a desenvolver um estudo sobre religião que privilegiasse um recorte "transversal" no fenômeno a ser pesquisado. Fugir da exclusividade dos aspectos internos às denominações religiosas a fim de estudar o fenômeno religioso "em relação", tanto entre as religiōes entre si como com outras dimensões da vida social. Em relação a primeira intenção, as relações das religiōes entre si, se justifica a prioridade de estudar o fenômeno religioso na cidade; em relação a segunda intenção, as relações entre a religião e as outras dimensóes da vida social, se justifica a ênfase nos aspectos de proteção social forjados na ação religiosa. A assistência social foi um campo privilegiado, para que a pesquisa pudesse dar conta das relações entre religião e política. No meu ponto de vista, a preocupação com as "questôes sociais" insere as religiôes, junto com outros atores sociais, no esforço de constituir ou influenciar a constituição de espaços societários capazes de garantir "boas condições de vida"; ou seja, mostra a intenção de contribuir na definição de "bem comum", tarefa própria à política do mundo moderno.

Para entrar nesse debate, minha opção foi dar conta de um "desconforto" que tive ao retomar as pesquisas sobre religião depois de meu primeiro ensaio para a dissertação de mestrado (Pereira Neto, 1995) e notar a adesão muito forte dos pesquisadores à definição da religião contemporânea como algo pertinente à vida privada das pessoas, sem "plausibilidade" na configuração do espaço público contemporâneo. De antemão, já anuncio que acho essa perspectiva uma redução do fenômeno religioso a uma classificação da sociedade em expressōes de natureza pública e de natureza privada. Essa, entre outras dicotomias, sofre com a multiplicidade das relações societárias contemporâneas e com os desafios de produzir uma hierarquização de sentidos pertinente e capaz de elucidá-las.

Nos anos $90^{3}$, o fenômeno empírico religioso de maior significação estatística era a expansão do pentecostalismo na sociedade brasileira e, como contraponto, a diminuição dos que se definiam como católicos. Espíritas

3 IBGE, Censo Demográfico 2000.

Debates do NER, Porto Alegre, ANo I4, N. 24, P. I95-22I, JUl./DEZ. 2013 
kardecistas e as religiões afro-brasileiras demonstravam uma estagnação em número de adeptos e, como novidade além do crescimento pentecostal e a presença dos new age e dos sem religião como expressão da religiosidade contemporânea no Brasil - estes últimos aparecem na bibliografia de autores brasileiros nos anos 2000. Isso foi visto como um aumento da possibilidade de escolha individual para decidir sobre a adesão religiosa e a caracterização de uma religiosidade mais privatizada, uma vez que a ênfase do pentecostalismo é na transformação do comportamento moral dos adeptos. Esses dados estariam apontando para a intensificação dos valores democráticos e modernos na sociedade brasileira.

Em função de certa simpatia com a tese de um potencial criativo do universo simbólico das religiôes em constituir sentidos societários particulares (desde que percebidos como constituídos por sua relação com as dimensões universalizadas da realidade), e ainda influenciado pela pesquisa anterior sobre o kardecismo, onde percebi forte influência desse imaginário religioso na constituição das relações de seus adeptos no espaço público, me propus estudar a presença (ou ausência) da religião no espaço público. Naturalmente, minha intenção com a pesquisa era problematizar o próprio âmbito do conceito que escolhia - o de espaço público ${ }^{4}$ - como um dos demarcadores da mesma. Como questão teórica, refletir sobre se o aumento da possibilidade de escolha individual para a adesão religiosa passa necessariamente pela ausência da influência religiosa no espaço público. Surge daí meu interesse em estudar as iniciativas de proteção social das diferentes religióes em Porto Alegre. A opção de estudar as práticas de proteção social fez com que meu campo se localizasse em regiōes com maior fragilidade social, como as periferias das grandes cidades, e em instituições que desenvolvessem ações de proteção a populações carentes, destacando as práticas reconhecidas como expressão da caridade. É importante salientar que a categoria "caridade" é utilizada na linguagem de vários atores sociais, de diferentes adesôes religiosas, para descrever as ações que levam a algum tipo de solidariedade do grupo e a um

4 O conceito de espaço público está referenciado na obra de Habermas, especialmente em Habermas, Jürgen. Mudança estrutural da esfera pública. São Paulo: Tempo Brasileiro, 2003.

Debates do NER, Porto Alegre, ANo I4, N. 24, P. I95-22I, JUl./DeZ. 2013 
cuidado com o outro. Portanto, tornou-se uma referência pensar no universo religioso através de categorias que se abrissem para interfaces com outros locus de sentido que configuram a vida social - como o da política, por exemplo.

Sem dúvida, a definição do campo de observação foi um dos primeiros problemas que se colocaram, uma vez que nesta pesquisa eu desejava mudar a conformação da pesquisa anterior do campo, onde fiz um recorte clássico da antropologia da religião da época, estudando uma denominação religiosa específica, o espiritismo kardecista. Naquela pesquisa eu já havia percebido a dificuldade de descrever a religião ou a religiosidade kardecista com uma única configuração. Minha pesquisa em Cascavel/PR mostrou que o kardecismo mudava de forma considerável se fosse uma experiência da população das regiōes centrais de Cascavel, de maior poder aquisitivo, ou se fosse uma experiência de populaçôes periféricas da cidade, de menor poder aquisitivo. E mais do que isso, foi possível perceber o kardecismo com um referencial simbólico para o diálogo entre essas diferentes populaçôes da cidade, um diálogo que definia aproximaçóes, mas também distanciamentos através das hierarquias que surgiam pelas elaborações sobre práticas e valores que a experiência religiosa proporcionava.

Minha preocupação em pesquisas futuras era, impulsionado por descobertas anteriores, investir na dimensão comunicacional entre os universos religiosos, especificamente no que esses elementos trazem de contribuição para a conformação de diferentes espaços societários na cidade. Espaços esses constituídos por uma "linguagem religiosa" e que se constituem em lugares de sentido que possibilitam ou dificultam o estar junto na complexidade do tecido urbano.

Como foi colocado anteriormente, lidar com a diversidade religiosa e, especificamente, perceber a presença da dimensão religiosa na conformação de espaços societários na cidade, passou a ser o interesse de pesquisa. A questão era conformar um campo de observação, mesmo que as expressões religiosas nas periferias das cidades continuassem um de meus focos de interesse, via a necessidade de não submeter o entendimento das mesmas a uma dimensão de classe social fixada por sua inscrição territorial. Meu interesse era também perceber o quanto a inserção dos indivíduos em determinados

Debates do NER, Porto Alegre, ANo I4, N. 24, P. I95-22I, JUl./DEZ. 2013 
universos religiosos permite a relação com outros espaços sociais, levando a um deslocamento dos indivíduos em relação ao seu lugar sociocultural original, ou mesmo levando à transformações desses mesmos lugares. Nesse aspecto, a intenção da pesquisa foi dar ênfase numa dinâmica da diversidade religiosa através da percepção das relaçōes que se davam com as religiōes entre si e com outros espaços de configuração do espaço público na cidade. Conceitos como o de fluxo (Hannerz, 1998) e o de rede (processualistas ingleses: Elizabeth Bott, 1976; Barnes, 2010) foram fundamentais para que eu definisse o olhar sobre o meu objeto de pesquisa. Daí saiu o título inicial de minha primeira pesquisa sob este ponto de vista: A expressão pública da religião em Porto Alegre.

\section{O QUE OS DADOS DA PESQUISA TROUXERAM}

Os dados iniciais da pesquisa foram coletados em 1998 e 1999, os quais foram utilizados em minha tese de doutorado. Como coloquei anteriormente, meu interesse foi o de me aproximar de pessoas, grupos e instituições que desenvolvessem iniciativas que visassem a proteção social e o cuidado com grupos vistos como fragilizados socialmente. Resolvi iniciar o trabalho por um universo mais conhecido para mim, no caso, os grupos kardecistas. Os primeiros contatos foram em uma instituição espírita localizada na zona central da cidade. Esta instituição desenvolvia uma série de práticas assistenciais: mantinha uma creche e um albergue masculino e feminino, além de algumas oficinas profissionalizantes, tendo a padaria-escola e a oficina de corte e costura entre as mais importantes. À diferença da outra pesquisa, meu interesse agora era menos nas atividades rituais e no reconhecimento da cosmovisão religiosa e mais nas práticas assistenciais que o grupo desenvolvia e nas suas motivaçôes. Interessavam-me as relaçóes que estavam sendo desenvolvidas pelo grupo espírita a partir de suas atividades assistenciais. Era preciso dar conta de uma das questóes principais da pesquisa, ou seja, se as atividades desenvolvidas pela instituição religiosa apresentavam alguma especificidade ou se integravam uma lógica universal da ação social na cidade, e se estavam efetivamente motivadas por uma política de alcance

Debates do NER, Porto Alegre, ANo I4, N. 24, P. I95-22I, JUl./DEZ. 2013 
mais amplo. Como é comum quando fazemos perguntas tão estanques ao campo, ele não nos mostra nem uma coisa nem outra, mas uma coisa e outra e a necessidade de hierarquizar esses elementos numa explicação plausível para a realidade expressa por suas interações.

O interessante numa grande instituição espírita é que ela expressa um organograma muito bem construído, com diferentes departamentos e setores organizados com funções próprias, alguns mais voltados para as questões espirituais e para as questôes de formação religiosa e outros para questôes assistenciais, ou melhor dizendo, para o desenvolvimento da caridade. Os primeiros contatos com essas instituiçóes anunciam a existência de um espaço ordenado, com uma organização capaz de lidar com responsabilidade das tarefas a que se propõe. A imagem modelar de uma instituição é muito bem representada pelo apreço à organização que o ethos espírita apresenta, pois é possível perceber diferentes funçôes nas partes que constituem o todo. Essa característica é vista como um valor entre os praticantes e mesmo entre as pessoas que utilizam seus serviços espirituais ou assistenciais. Isso leva a que esse sentido de organização institucional seja um valor importante na conformação da experiência espírita.

A princípio, essa ênfase na organização de sua estrutura produz uma expectativa de uma ação ordenada nas diferentes instâncias que compõem a instituição. E mais, nos faz esperar que as ações expressem um "conteúdo espírita”, produzido pelos elementos ideológicos de sua cosmologia e pelo exercício das práticas rituais. Porém, a observação mais atenta do dia a dia da instituição e de seus diferentes setores e atores mostra que a realidade não é bem essa. O que se observa é que existe uma autonomia considerável das pessoas que estão à frente das diferentes instâncias que compõem a instituição. Isso é menos verdadeiro para as instâncias que lidam com as atividades de espiritualização, as quais contam com orientações mais estritas sobre sua forma de execução. Afinal, são atividades diretamente relacionadas com a construção e reprodução da crença. Porém, mesmo aqui, percebe-se certa autonomia no desenvolvimento das práticas religiosas, o que algumas vezes gera debates e disputas entre os praticantes sobre a melhor condução dos trabalhos espirituais. Não dá para esquecer que uma das características

Debates do NER, Porto Alegre, ANo I4, N. 24, P. I95-22I, JUl./DEZ. 2013 
marcantes da cosmologia espírita é o lugar de destaque que ela confere para o livre-arbítrio e, portanto, para a autonomia individual.

Essa autonomização fica explícita na condução dos trabalhos assistenciais. Como uma instituição religiosa, ela conta com a dificuldade de suas atividades serem voluntárias. No caso da creche e da padaria-escola, havia funcionários remunerados que não eram espíritas. Havia projetos que mantinham a sua remuneração (SENAC e Prefeitura Municipal). Por outro lado, os voluntários (adeptos ao espiritismo) que conduziam os trabalhos geralmente precisavam compartilhar essas atividades com as que lhe davam sustento financeiro. Assim, é comum que muitas das pessoas responsáveis pelas atividades na instituição já estejam afastadas de suas atividades profissionais, ou que as mesmas permitam uma divisão do tempo entre estas atividades e as atividades no centro espírita. O fato é que, ao assumir as funçôes na instituição e, em especial, as atividades assistenciais, as pessoas colocam sua marca. São atividades que exigem muita doação das pessoas e, portanto, quem assume o trabalho conquista alguma autonomia. Assim, ao observar as atividades assistenciais da instituição, me deparei com formas de trabalho e com concepçõos distintas na constituição dos processos de assistência social.

Como exemplo, é suficiente destacar o trabalho na creche e o trabalho na oficina de corte e costura. Na creche, a coordenação estava à cargo de uma professora que à época estava licenciada da rede pública de ensino e trabalhava numa escola particular da cidade. Tratava-se de uma pessoa de fala muito bem articulada, com um discurso claro e seguro. Apresentava com orgulho o trabalho na creche, a organização do espaço físico, a sua equipe de trabalho em grande parte remunerada - e o currículo, pensado e discutido de acordo com os parâmetros mais recentes da pedagogia infantil. É claro que o fato de ser espírita dava sentido a sua presença naquele espaço, mas a coordenadora deixava claro que não havia nenhum tipo de proselitismo religioso através das atividades da creche (a mensagem religiosa efetivamente não era explícita, mas subliminar). A observação do trabalho da equipe de educadores mostrava pessoas motivadas e com uma relação intensa e afetiva com as crianças. $\mathrm{O}$ vigor do trabalho era explicado pelo envolvimento das pessoas da equipe remuneradas e não remuneradas - e pelos recursos extras (além dos recursos

Debates do NER, Porto Alegre, ANo I4, N. 24, P. I95-22I, JUl./DEZ. 2013 
da instituição espírita) que advinham de aportes da prefeitura e que permitiam sustentar o trabalho. Essa dimensão profissional do trabalho era construída pela equipe da creche e era muito apreciada pelos técnicos da prefeitura. A creche da instituição era vista como um lugar que explicitava a política da prefeitura de evitar que elas se transformassem em um "depósito de crianças".

Outra lógica de ação vigorava na condução da oficina de corte e costura. Assim como a creche, as oficinas atendiam famílias de baixa renda. No caso da creche, crianças filhos e filhas de mães trabalhadoras. No caso da oficina, mulheres que estavam à procura de trabalho e investiam numa profissionalização. A diferença é que a oficina contava com recursos limitados ao que a instituição podia oferecer de recursos próprios. Evidentemente, os recursos eram poucos, e assim contavam com a boa vontade da coordenadora da oficina para continuar a atividade. Os equipamentos, normalmente de segunda mão, eram conseguidos através de doações e as aulas eram ministradas por mulheres da instituição espírita que tinham conhecimento da atividade ou por antigas alunas que se prontificavam a doar parte de seu tempo para auxiliar no desenvolvimento das oficinas. As relações na oficina eram marcadamente pessoalizadas, sem nenhuma mediação de um discurso de profissionalização da atividade, como acontecia na creche.

Havia certo mal-estar entre as responsáveis pela coordenação das atividades de "caridade". De um lado, a coordenadora da oficina de corte e costura acusava a creche de drenar a maior parte dos recursos da instituição. Por outro, a coordenadora da creche afirmava que os recursos suplementares vinham de fora, em função dos projetos apresentados para a prefeitura, e que as outras coordenadorias deveriam fazer o mesmo.

Porém, o que importa desses exemplos de campo é que eles conformam tipos de conexão que esses diferentes espaços acabaram desenvolvendo com outros grupos que promoviam trabalhos similares na cidade. Os contatos com a creche me levaram a conhecer o CMDCA (Conselho Municipal dos Direitos da Criança e do Adolescente) e o FMDCA (Fórum Municipal dos Direitos da Criança e do Adolescente) de Porto Alegre, organismos de representação da sociedade civil na gestão da política pública para a criança e o adolescente. Ao passo que os contatos com a oficina de corte e costura me

Debates do NER, Porto Alegre, ANo I4, N. 24, P. I95-22I, JUl./Dez. 2013 
levaram a conhecer lideranças comunitárias de diferentes vilas - denominação local para espaços periféricos de baixa renda de Porto Alegre (Nossa Senhora de Fátima, no Bairro Glória, e Vila Tronco, uma região habitada por uma população de baixa renda e que está interposta entre bairros de elite na cidade).

Em uma perspectiva típico-ideal, podemos classificar o modus operandi próprio à ação dos que desenvolviam o trabalho na creche como de imposição da racionalidade técnica e da meritocracia na orientação das atividades assistenciais; já a ação dos que desenvolviam a atividade na oficina de corte e costura partia da ênfase em relaçôes personalizadas que comporiam uma espécie de camaradagem afetiva entre os participantes e que, por extensão, é a base do que poderíamos definir em outros espaços como compromisso comunitário. Nos dois casos, as ações eram referendadas por elementos da cosmovisão sagrada do espiritismo. Porém, ao passo que o trabalho na creche aderia ao ideal da evolução espiritual através do aperfeiçoamento individual, característico do espiritismo, o trabalho da oficina contava, por outro lado, com elementos legitimadores mais amplos do mundo católico, como o mérito conquistado pela doação aos necessitados. Evidentemente que essas lógicas eram representadas por grupos que encurtavam seus laços e produziam algum tipo de fidelização que passava por relações pessoais. A diferença é que para um dos grupos a pessoalidade era a referência pública para a ação, enquanto no outro caso a legitimidade da ação também passava por critérios de mérito pela qualificação do trabalho.

O desdobramento das relações observadas na instituição espírita serviu como referência para que a pesquisa pudesse se expandir para outros universos de observação na cidade. De certa forma, posso defender que a visão da pesquisa sobre a presença pública da religião na cidade foi constituída juntamente com um conjunto de referências espíritas do problema. Como já coloquei anteriormente, os contatos a partir da instituição apresentaram duas facetas da construção do cuidado em Porto Alegre: 1) numa delas estava a rede mais formalizada, relacionando-se com os organismos do município através de uma lógica mais próxima do que os agentes do poder público imaginavam como uma ação cidadã, ou seja, uma relação "correta" no espaço público. Como já foi colocado, os contatos através da creche me

Debates do NER, Porto Alegre, ANo I4, N. 24, P. I95-22I, JUl./DeZ. 2013 
levaram, com certa surpresa para mim, a um contato mais estreito com os órgãos de representação da sociedade civil para a promoção de políticas públicas, como o CMDCA e o FMCDCA. Os vínculos da coordenadora da creche eram, por exemplo, com um diretor da ACM, responsável pelo trabalho assistencial da entidade, e à época coordenador do CMDCA, e com um padre franciscano, responsável pelo trabalho assistencial com crianças na Lomba do Pinheiro, região da periferia de Porto Alegre. 2) Noutra faceta, nos deparamos com uma rede menos formalizada, mais dependente das negociações próprias às relações pessoais e mais resistente a processos de padronização que retirassem o foco das decisões do contexto das localidades ou, no dizer dos interlocutores, da "comunidade". Os contatos através da oficina de corte e costura me levaram a um líder comunitário que mantinha uma creche na vila $\mathrm{Ns}^{\mathrm{a}}$ de Fátima, no bairro Glória. Esta pessoa frequentava o centro espírita, mas não de forma sistemática. O outro contato era outro líder comunitário, desta vez na Vila Tronco, próxima ao Bairro Santa Tereza. Este, além de líder comunitário, era pai de santo. Mantinha uma creche e uma cooperativa de reciclagem de alimentos na Vila Tronco 5 .

Essa configuração do campo através de redes constituídas a partir dos contatos na instituição espírita permitiu, por um lado, que eu resolvesse o problema de delimitação do campo, e por outro, levou a uma reformulação nos objetivos da pesquisa. $\mathrm{O}$ foco no trabalho assistencial com crianças conduziu as observações a instituições ou grupos religiosos. Há uma ênfase no trabalho com crianças por parte das organizaçôes religiosas. Além disso, a rede

5 No caso deste líder comunitário, ficava explícita a base territorial das relaçôes de poder em que estava envolvido. Além de seu histórico à frente da associação de moradores do bairro, da qual estava momentaneamente afastado à época da pesquisa, mantinha um complexo de atividades desenvolvidas em prédios que ficavam em terrenos contíguos e que eram de sua propriedade. Funcionava ali uma creche infantil - sendo que à entrada desta havia uma bandeira do Partido dos Trabalhadores; uma cooperativa de distribuição e venda de produtos reciclados, uma oficina de separação de lixo, a moradia da família e, ao fundo do terreno, o terreiro de religião afro-brasileira que ele comandava como pai de santo. Neste, ele mantinha a placa de inauguração onde constava a presença de políticos de um partido adversário do Partido dos Trabalhadores. Ele costumava insistir que não gostava de políticos.

Debates do NER, Porto Alegre, ANo I4, N. 24, P. I95-22I, JUl./DEZ. 2013 
de relações permitia o contato com a diversidade de propostas de proteção, sem deixar de lado as conexões entre os agentes, permitindo investir numa problemática que fosse pertinente à realidade das diferentes iniciativas. Foi em função disso que a pesquisa passou a se interessar pelo problema da participação dos representantes dos grupos religiosos e/ou comunitários nas instâncias de definição das políticas públicas para crianças e adolescentes na cidade. Não é demasiado lembrar que no período do trabalho de campo a cidade estava vivendo a proposta de participação direta da população na gestão pública, proposta pelo governo do Partido dos Trabalhadores e que tinha como instrumento político-administrativo principal o sistema do orçamento participativo.

O entusiasmo em relação ao projeto de participação popular proposto pela prefeitura era evidente entre os membros que dirigiam o CMDCA e o FMDCA. Viam na estrutura dos conselhos e dos fóruns uma possibilidade efetiva de participação da população nas políticas públicas do poder público. Além disso, se percebia a potencialidade desses organismos em estender a influência das propostas do poder público para as ideias e para as práticas que sustentavam o trabalho de proteção social desenvolvido pelas instituições da cidade. Para exemplificar, na época em que fazia a pesquisa junto ao FMDCA, sua coordenadora estava empenhada num trabalho, conjunto com a Secretaria Municipal de Educação, de melhorias na estrutura e de orientação pedagógica nas creches assistenciais. Estavam sendo oferecidos cursos de capacitação para as pessoas envolvidas no trabalho com as crianças. Além disso, para a liberação dos recursos oferecidos pela prefeitura para essas instituiçóes estava sendo exigida a formulação de projetos que planejassem não só a alocação dos recursos, como também a sua destinação para atividades consideradas pelos agentes públicos como adequadas para o aprimoramento das atividades nas creches.

A força deste movimento de promover a participação direta da população alcançou de forma intensa a rotina dos grupos e instituições que faziam o trabalho de cuidado à criança e aos adolescentes. Essa situação levou a pesquisa a ampliar seu locus de observação para os conselhos e fóruns de participação. Além do trabalho junto às entidades para entender suas 
dinâmicas específicas, surge a necessidade de acompanhar a atuação de seus representantes junto aos organismos de participaçãa ${ }^{6}$.

Neste fluxo entre o trabalho de observação nas entidades de proteção social da cidade e nos conselhos de participação, são retiradas as principais conclusões do trabalho. Entre elas:

- A adequação dos valores e princípios organizacionais das instituições e grupos de cristãos letrados (entre eles os católicos e protestantes da teologia da libertação e os representantes do kardecismo letrado) à visão de gestão política da cidade proposta pelo orçamento participativo.

- A importância do trabalho de mediação desenvolvido pelas agências religiosas acima referidas na implantação das políticas públicas gestadas na estrutura de gestão participativa junto à população atendida. Nesse caso, a mediação também passa por processos de imposição de poder segregacionistas, mesmo com a perspectiva democrática das estruturas de poder. Havia processos implícitos, formulados muitas vezes nos fóruns de participação popular, que definiam quem teria acesso aos recursos.

- A dificuldade de grupos e instituições com uma organização baseada no personalismo de cumprir as exigências dos princípios organizacionais estabelecidos pela "lógica do projeto". Normalmente, isso implicava em dificuldades para receber recursos públicos e, portanto, num incremento de formas autônomas de financiamento de suas atividades, e na busca de "burlar" as exigências burocráticas. Na perspectiva dos agentes públicos, tratava-se de vencer o clientelismo inerente às relaçôes de poder na periferia. Dos líderes comunitários ouvia-se a queixa pela falta de um

6 As observações deixaram evidente a presença de uma "etiqueta" que conduzia a atuação dos participantes das reuniões. Havia performances de participantes que traziam vantagens para os mesmos nos momentos de definição das políticas e dos investimentos do CMDCA. O protagonismo nas reuniōes era daqueles que se mostravam mais participativos e "conscientizados". Aqueles que em suas propostas defendiam critérios administrativos que defendessem o "bem comum".

Debates do NER, Porto Alegre, ANo I4, N. 24, P. I95-22I, JUl./Dez. 2013 
"rosto" para negociar com o poder público: "[...] é difícil conversar com o PT, eu prefiro conversar com uma pessoa" - manifestação de uma das lideranças. A adesão religiosa dessas lideranças muitas vezes passava por um tipo de organização que valorizasse as "relações de vizinhança" e um "sistema de prestigio" decorrente dessas relaçóes, como alguns grupos afro-brasileiros e pentecostais.

Essas conclusões nos remetem a uma conexão importante das dimensões religiosa e política envolvidas na questão. Aqui nos parece importante ressaltar dois movimentos importantes para entender esse aspecto. Em primeiro lugar, a pesquisa de Porto Alegre demonstrou que ao integrar a dimensão política dada pela ação dos agentes e instâncias do poder público nos processos de proteção social, ficou evidente o problema da legitimidade para as agências religiosas envolvidas no processo. Há um direcionamento para o reconhecimento de uma lógica determinante das relaçóes no espaço público, e esta lógica passa por uma definição de coletividade proposta por referências morais estabelecidas pelo campo cristão de caráter racionalista, especialmente o católico. Noções de "comunidade" presentes nas referências ideológicas da Teologia da Libertação, assim como a noção de indivíduo racionalmente concebido, presente na cosmologia kardecista, são elementos importantes para objetivar a perspectiva de sociedade a ser instaurada pela ação política da prefeitura. Não há como deixar de lembrar aqui as questões que Giumbelli $(2003$; 2011) levanta sobre as relaçôes de poder envolvidas na definição do conceito de religião e suas implicaçôes na constituição das sociedades modernas, especialmente a forma como essa definição passa pelos sentidos de valor que ordenam a estrutura jurídica do Estado moderno. Em segundo lugar, e como decorrência desse primeiro apontamento, destaca a importância dos estudos atentarem para a imagem de sociedade e/ou coletividade e para o universo simbólico das diferentes expressões religiosas que configuram o espaço societário de nossas cidades. Sobre esse ponto, creio que é possível tratar das questóes próprias à diversidade religiosa sem submeter seu entendimento à referência exclusiva do conceito de pluralismo religioso. Esse conceito, apesar de ser muito útil para entender a modernidade, tende

Debates do NER, Porto Alegre, ANo I4, N. 24, P. I95-22I, JUl./DeZ. 2013 
a conceber sua dinâmica referenciada quase que exclusivamente na realidade europeia. As possibilidades da criatividade simbólica dos fenômenos religiosos modernos, com sua necessidade incessante de renovação, podem ser mais bem compreendidas se apreendermos sua dinâmica de interconexões, seja no campo religioso ou fora dele, quando expressa sua contribuição na construção do sentido de um espaço coletivo que ao mesmo tempo em que se abre para novos arranjos (ideias como a de laicidade e de democracia são garantias desta predisposição das estruturas do Estado moderno), precisa constituir referências morais que garantam a condição de "vivermos juntos".

\section{PROBLEMA DE PESQUISA GERADO}

Uma questão que ficou desta primeira fase da pesquisa: investigar sobre os "sentidos de comunidades" gerados na diversidade da experiência religiosa das periferias da cidade. A convicção criada é a de que o Estado constitui-se através de uma lógica que exige, para sua legitimidade, a negociação com lógicas distintas do que é "estar junto", ou seja, seu sentido de totalidade passa pela relação de suas instâncias com outros "sentidos de comunidade" presentes na sociedade:

Se a democracia, enquanto equivalente político do Estado nação obteve êxitos, eles se devem à sua capacidade de construir uma ordem coletiva contendo: 1) por um lado uma parte privativa da existência, na qual o indivíduo pode legitimamente interpretar a seu modo o sentido último da vida e de outros "valores perenes"; 2) por outro lado, possibilitando um estar junto em torno de escolhas coletivas (Barbosa; Pereira Neto, 2008, p. 5).

É próprio do Estado articular-se através de uma metafísica que abre para a universalização das relaçōes e que, por sua vez, só se objetiva através dos sentidos dados no trabalho de construção de uma unidade moral da coletividade. Esse processo é necessariamente conflituoso por articular valores próprios do nível local, fundamentais para garantir a participação das pessoas numa comunidade política, com princípios de organização do Estado, que afirma de forma transcendente a liberdade de crença, de consciência e a

Debates do NER, Porto Alegre, ANo I4, N. 24, P. I95-22I, JUl./DEZ. 2013 
própria existência privada dos indivíduos. A reflexão sobre diversidade religiosa, multiculturalismo e outras expressões da fragmentação da vida social responde a busca de elementos que possam articular novos princípios de constituição de um "corpo coletivo artificial" que justifique o poder do Estado.

É preciso reconhecer a crise dos princípios do Estado secular moderno, onde os elementos de sentido são dados pela perspectiva civilizatória do iluminismo. Dessa forma, justifica-se explorar processos que implicam em movimentos de ordenação coletiva e suas consequências para a conformação de novos espaços societários. No caso desta pesquisa, as práticas e as narrativas religiosas das periferias das cidades são tomadas como expressões significativas, que agem como protagonistas no processo de (re)criação de espaços societários, possibilitando ou inibindo novos ordenamentos simbólicos que justifiquem o espaço do vivido para essas populaçôes ${ }^{7}$. Aqui também assumimos que a condição marginal e/ou de fronteira dessas populações potencializa a descoberta de elementos críticos à estrutura social dominante.

Em pesquisas desenvolvidas em Juiz de Fora/MG, a ênfase foi na presença dos grupos e agentes religiosos no cotidiano da periferia, especialmente para entender os sentidos de comunidade articulados nesses espaços. Sem a presença do poder público de forma tão efetiva como em Porto Alegre, a pesquisa se desenvolveu sustentada por uma base territorial, o bairro Teixeiras, menos calcada na perspectiva de rede que se estabeleceu na observação em Porto Alegre. Não que em Juiz de Fora as conexões entre

7 Reforço a importância dos estudos na cidade para entender as dinâmicas contemporâneas da diversidade, trazendo a defesa que Michel Argier faz de uma Antropologia da cidade: "É essa a abordagem que defendo aqui, partindo de duas operações de ordem epistemológica necessárias a uma antropologia da cidade, considerada como aplicação de uma antropologia social e simbólica dos espaços contemporâneos: primeiro, deslocar o ponto de vista da cidade para os citadinos - e assim, parafraseando Clifford Geertz quando fala de cultura, ver a cidade como vive, olhando-a 'por cima do ombro' dos citadinos; em segundo lugar, deslocar a própria problemática do objeto para o sujeito, da questão sobre o que é a cidade - uma essência inatingível e normativa - para a pergunta sobre o que faz a cidade. $\mathrm{O}$ próprio ser da cidade surge, então, não como um dado mas como um processus, humano e vivo, cuja complexidade é a própria matéria da observação, das interpretaçōes e das práticas de 'fazer cidade"'(Argier, 2011, p. 38).

Debates do NER, Porto Alegre, ANo I4, N. 24, P. I95-22I, JUl./DEZ. 2013 
os diferentes grupos religiosos estivessem ausentes. A questão é que a ênfase na dimensão política dos processos anteriores potencializou a percepção dos elementos de força presentes na produção simbólica dos grupos religiosos. Os espaços de observação - um grupo católico de ação pastoral ${ }^{8}$, um centro kardecista e uma congregação da igreja quadrangular - não me colocaram em relação uns com os outros através das atividades que desenvolviam. Portanto, sem a articulação da dimensão política, o contato entre os grupos se dava de forma muito mais esparsa e desarticulada. Essa situação conduziu a pesquisa a focar na especificidade da ação simbólica dos grupos religiosos, sem deixar de considerar que as configuraçóes ali encontradas, apesar de certa "autonomia" sugerida pela observação, não deixavam de constituir-se por processos de interação com elementos religiosos e não religiosos presentes na vida coletiva da cidade. A política aqui aparece como elemento circunstancial (mas presente).

Nesse caso, o que se estabeleceu foi a imagem de uma "tipologia da presença" de diferentes grupos religiosos no bairro pesquisado. O interesse de tal abordagem está em demarcar de forma mais clara os elementos simbólicos presentes na constituição da experiência subjetiva nos diferentes grupos. Deixar mais claro os "particularismos" (Wagner, 2010) que se colocam em relação com os elementos da norma instituída na política das cidades modernas. Portanto, muito antes de descrever esses espaços religiosos como produtores de uma cosmovisão exclusiva, o que se procurou foi destacar elementos particulares que podem estar sustentando princípios de moralidade que são referências para a construção dos vínculos legítimos no espaço público. Eis alguns exemplos desses elementos que imagino serem referenciais:

1. A presença católica é a que propiciava maior repercussão para as políticas públicas desenvolvidas no bairro. A participação em algumas

8 A escolha pelo projeto de ação pastoral católica para a observação e não do templo católico que fica localizado à entrada do bairro, na parte alta e rodeado de residências de um padrão socioeconômico mais alto em relação à configuração média do bairro, tem como objetivo trabalhar com espaços religiosos mais inseridos nos dia a dia do bairro. Essa condição se efetiva de forma mais clara nas atividades desenvolvidas na sede da pastoral, inserida no coração do bairro.

Debates do NER, Porto Alegre, ANo I4, N. 24, P. I95-22I, JUl./DEZ. 2013 
dessas iniciativas mostrava-se contemplada no "ser" e no "fazer" católico do local. Aqui chama a atenção uma característica que não havia ficado explícita na primeira fase da pesquisa, ou seja, a influência do imaginário sagrado na objetivação de uma presença administrativa de base territorial, onde os limites das paróquias determinavam a ação no bairro, muitas vezes demarcado por imagens sagradas. Grutas com imagens de Nossa Senhora ou de santos, a cruz em locais estratégicos do bairro, e nomes de santos para localidades expressam na paisagem a presença encompassadora do sagrado católico. Numa religiosidade marcada por imagens e pela ritualização que envolve os sacramentos, essa presença na paisagem oferece para os adeptos, mas também para os que compartilham de forma menos intensa o imaginário católico, a dimensão de Deus como protetor de todos. Parece-me que essa perspectiva espacial sustenta a certeza dos adeptos do catolicismo de que, mesmo diante da presença das diversas expressões do sagrado, no final das contas todos são filhos de Deus, obviamente de um Deus cristão com matizes católicos. Não é demasiado sugerir que essa perspectiva de domínio católica tem correlaçōes importantes com o estabelecimento dos sentidos de comunidade que legitimam o imaginário da sociedade nacional estabelecida pelo Estado moderno. Foi marcante em Teixeiras o fato de que os sentidos de pertencimento e mesmo a ação dos adeptos estavam sendo sempre referenciadas pelas regiōes administrativas à qual o mesmo pertencia. Havia uma prioridade pelo trabalho social no território a que pertenciam e, posteriormente, a possibilidade de estender a ação para outros territórios, formando redes que poderiam prosperar desde que os compromissos comunitários/territoriais estivessem sendo beneficiados por esse tipo de ação.

2. A presença espírita como um "enclave" civilizador no bairro. Nesse caso, a ação não se espalha entre os "pobres” do bairro, mas fica restrita ao espaço do centro (denominação do templo religioso kardecista) onde, nas suas atividades assistenciais e espirituais, ocorre o encontro entre os dois grupos. Os administradores do centro, tanto em seus aspectos materiais como assistenciais e espirituais, vêm de fora do bairro (lugares

Debates do NER, Porto Alegre, ANo I4, N. 24, P. I95-22I, JUl./DeZ. 2013 
mais abastados da cidade) para propor uma "visão do ser" específica para os moradores do bairro. Essa visão é sustentada pelos princípios evolucionistas da existência espiritual, própria à cosmologia espírita, e pela moralidade sustentada pela ideia de livre-arbítrio e de autorresponsabilização do indivíduo. A ênfase é no indivíduo e em seus atos, os quais são hierarquizados pela moralidade própria ao imaginário kardecista da evolução do espírito da pessoa. Mesmo pregando autonomia individual, a relação entre atendentes e atendidos é de tutela dos primeiros em relação aos segundos. Na visão dos atendentes, é necessário que a experiência do centro traga o "esclarecimento" aos habitantes do bairro. Evidentemente, a adesão dos moradores do bairro às atividades propostas é razoável em termos numéricos e baixa em termos de adesão ao ideário espírita. Poucos moradores passam à condição de atendentes e aderem ao ethos kardecista. Na maioria, se comportam como necessitados em busca de recursos materiais e que, para tanto, se submetem a alguns trabalhos de espiritualização e esclarecimento. Por outro lado, a experiência no centro permite a pessoas de grupos sociais mais abastados manterem uma relação próxima ao "outro", representado pelos moradores da periferia. Médicas, odontólogos e advogados experimentam a relação de doação com os pares "em dificuldade momentânea". Nesse caso, há um efetivo processo de sensibilização para outras realidades, mas as hierarquias sociais são mantidas.

3. A presença pentecostal através da presença de um grupo de fé, pouco dependente do território e muito da adesão a uma "comunidade de salvos". Aqui as relaçôes entre praticantes são horizontais e menos hierárquicas, especialmente se levarmos em conta os demarcadores sociais. O que importa aqui é a constituição de uma congregação, uma comunidade de salvos. As ações não destacam a caridade, mas sim a ajuda mútua. Não há pobres a ajudar, há irmãos a resgatar. $\mathrm{O}$ interesse dos adeptos é em participar das atividades rituais, muito animadas e com música, e onde as pessoas são estimuladas a expressar a presença de Jesus e de Deus dentro delas. Aqui há uma característica interessante em termos 
de frequência. Mesmo com muitas pessoas da vizinhança presentes, há um bom número de pessoas de outros bairros. Mesmo o pastor e sua família, que dirigem o culto, são de outro bairro da cidade. Não há um compromisso com uma comunidade com base territorial - como no caso católico, mas sim com uma comunidade pautada num compromisso da pessoa com a divindade. Esse fator permite que a vivência no grupo religioso forneça um "outro registro" sobre suas vidas. Não foram poucos os casos em que, através da linguagem religiosa, fossem narrados processos interessantes de reflexão sobre os acontecimentos de suas vidas. Antigos compromissos e fidelidades são questionados - adesão religiosa e compromissos com parentela - em favor de um compromisso da pessoa com a divindade e com um eu sagrado. Sem dúvida, estamos diante de processos reflexivos e de individuação muito interessantes e que não passam - por exemplo - pela incorporação do indivíduo (ou espírito) em evolução do modelo kardecista.

Este breve exemplo da criatividade, da religiosidade e dos processos de subjetivação presentes nos espaços periféricos de nossas cidades nos aponta para a presença de diferentes locus de produção de um imaginário importante sobre o ordenamento das relaçóes societárias no tecido urbano. Penso que nesses espaços está sendo trabalhada constantemente tanto a compreensão dos indivíduos no mundo como a sua possibilidade de "estarem juntos", ou seja, a sua condição de vida comum. O fato da dimensão política não estar presente sempre com a mesma força faz parte das composiçõos específicas e históricas que o movimento de criação simbólica apresenta. Como lembra Leach (1996), não há uma relação necessária e direta entre expressão cultural e estrutura social, ou seja, o imbricamento entre relações políticas e religiosas é comum, mas não é condição para a sua existência mútua. Esse fato, no entanto, não retira as possibilidades que o simbolismo religioso oferece para a criação de conexões, por similaridade ou por contradição, de fluxos e mesmo de exclusões que constituem a vida social e suas relações políticas. Em se tratando da importância do imaginário (âmbito próprio ao religioso), não é demais lembrar a importância dos sentimentos na constituição do social, como faz Godelier:

Debates do NER, Porto Alegre, ANo I4, N. 24, P. I95-22I, JUl./DEZ. 2013 
Não se trata de negar a existência das três funçôes (o imaginário, o simbólico, e o "real") dessas três ordens que se combinam para compor a existência do social dos humanos, sua realidade social. O problema é saber se é possível construir representações mais adequadas a esta realidade afirmando que o simbólico domina o imaginário ou supondo o inverso. A nossos olhos, esta perspectiva inversa é a que se deve adotar. São antes de tudo as diversas maneiras como os homens imaginam suas relações entre eles com aquilo que chamamos de natureza que distinguem as sociedades, assim como as épocas durante as quais algumas delas continuam a existir. Mas o imaginário não pode se transformar em social, fabricar "sociedade", existindo apenas idealmente. Precisa materializar-se em relações concretas que tomam forma e conteúdo nas instituições e, claro, nos símbolos que as representam e fazem com que correspondam entre si, que se comuniquem. "Materializando-se" em relações sociais, o imaginário torna-se parte da realidade social (Godelier apud Campos, 2006).

Em se tratando do Estado como a estrutura política capaz de ordenar sentidos de totalidade para as sociedades contemporâneas, não é demasiado sugerir a atenção para estas "subjetividades alternativas" e o que elas podem nos oferecer em termos de inteligibilidade dos "modelos nativos" e das relações que os mesmos mantém com as instâncias de poder político. Se, como diz Foucault (Rabinow, 1999), a força do Estado está em ser tanto uma forma de poder totalizante como individualizadora, é importante que essa força individualizadora dê vazão a diversidade de suas formas expressivas para que a totalidade composta tenha alguma legitimidade. 


\section{REFERENNCIAS}

ARGIER, Michel. Antropologia da cidade: lugares, situações, movimentos. São Paulo: Terceiro Nome, 2011.

BARBOSA, Wilmar; PEREIRA NETO, Francisco. Sincretismo religioso, pluralismo e a sociedade pós-secular. In: XII Congreso Latinoamericano sobre Religion y Etnicidad: cambios culturales, conflicto y transformaciones religiosas. Bogotá/Colombia, 2008.

BARNES, John Arundel. Redes sociais e processo político. In: FELDMANBIANCO, Bela (Org.). Antropologia das sociedades contemporâneas. São Paulo: Editora UNESP, 2010.

BASTIDE, Roger. As religiões africanas no Brasil. São Paulo: Livraria Pioneira, 1971.

BOTT, Elizabeth. Familia e Rede Social. Rio de Janeiro: Francisco Alves, 1976.

CAMARGO, Procópio F. Kardecismo e Umbanda. São Paulo: Pioneira, 1961.

CAMPOS, Roberta B. C. O outro como fim: a caridade como mimesis do Deus. Implicações teóricas. In: MARTINS, Paulo Henrique; CAMPOS, Roberta Bivan C. (Orgs.). Polifonia do Dom. Recife: Ed. Univeristária da UFPE, 2006. p. 141-164.

CARVALHO, José J. Uma querela de espíritos: para uma crítica brasileira do suposto desencantamento do mundo moderno. Sociedade e Estado, n. 1, p. 63-87, jan./jun. 1986.

GIUMBELLI, Emerson. O "chute na santa”: blasfêmia e pluralismo religioso no Brasil. In: BIRMAN, Patrícia (Org.). Religiāo e espaço público. São Paulo: Attar, 2003. p. 169-200.

. A noção de crença e suas implicações para a modernidade. Horizontes Antropológicos, Porto Alegre, ano 17, n. 35, p. 327-356, jan./jun. 2011.

Debates do NER, Porto Alegre, ANo I4, N. 24, P. I95-22I, JUl./DeZ. 2013 
HABERMAS, Jürgen. Mudança estrutural da esfera pública. São Paulo: Tempo Brasileiro, 2003.

HANNERZ, Ulf. Cosmopolitas e locais na cultura global. In: FEATHERSTONE, Mike (Org.). Cultura Global: nacionalismo, globalização, modernidade. Petrópolis: Vozes, 1998. p. 251-266.

LEACH, Edmund R. Sistemas Politicos da Alta Birmânia. São Paulo: EDUSP, 1996.

MARCUS, George. Identidades passadas, presentes e emergentes: requisitos para etnografias sobre a modernidade no final do século $\mathrm{XX}$ ao nível mundial. Revista de Antropologia, São Paulo, n. 34, 1991.

PEREIRA NETO, Francisco. A caminho da luz: estudo sobre espiritismo e modernidade em Cascavel, oeste do Paraná. Dissertação (Mestrado em Antropologia Social) - Universidade Federal do Rio Grande do Sul, Porto Alegre, 1995.

PIERUCCI, A. Flávio. Reencantamento e secularização. A propósito do autoengano em sociologia da religião. Novos Estudos CEBRAP, São Paulo, v. 49, p. 99-117, 1997.

- Secularização em Max Weber: da contemporânea serventia de voltarmos a acessar aquele velho sentido. Revista Brasileira de Ciências Sociais, São Paulo, v. 13, n. 37, p. 43-73, 1998.

PRANDI, Reginaldo. Perto da magia, longe da política: derivações do encantamento do mundo desencantado. Novos Estudos CEBRAP, n. 34, nov. 1992.

RABINOW, Paul. Sujeito e governabilidade: elementos do trabalho de Michel Foucault. In: . Antropologia da razão: ensaios de Paul Rabinow. Rio de Janeiro: Relume Dumará, 1999. p. 27-53.

SANCHIS, Pierre. O campo religioso contemporâneo no Brasil. In: ORO, Ari; STEIL, Carlos Alberto (Orgs.). Globalização e Religiāo. Petrópolis, 
RJ: Vozes; Porto Alegre, RS: Universidade Federal do Rio Grande do Sul, 1997. p. 103-115.

SEGATO, Laura R. Formações de diversidade: nação e opções religiosas no contexto da globalização. In: ORO, Ari; STEIL, Carlos Alberto (Orgs.). Globalização e Religiāo. Petrópolis, RJ: Vozes; Porto Alegre, RS: Universidade Federal do Rio Grande do Sul, 1997. p. 219-248.

VELHO, Otávio. Globalização: antropologia e religião. In: ORO, Ari; STEIL, Carlos Alberto (Orgs.). Globalização e Religiāo. Petrópolis: Vozes, 1997.

WAGNER, Roy. A invenção da cultura. São Paulo: Cosac Naify, 2010. 